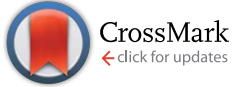

Cite this: RSC Adv., 2016, 6, 45986

\title{
High capacitive amorphous barium nickel phosphate nanofibers for electrochemical energy storage $\uparrow$
}

\author{
Teng Wang, ${ }^{a}$ Qingli Hao, ${ }^{b}$ Jinzhang Liu, ${ }^{c}$ Jiachang Zhao, ${ }^{d}$ John Bella \\ and Hongxia Wang*a
}

Ultrafine amorphous $\mathrm{Ba}_{x} \mathrm{Ni}_{3-x}\left(\mathrm{PO}_{4}\right)_{2}(0<x<3)$ nanofibers are synthesized for the first time through a facile cation exchange reaction method at room temperature. Both the phase transformation and growing process of the nanofibers are systematically investigated. A dramatic morphology transformation from $\mathrm{Ba}_{3}\left(\mathrm{PO}_{4}\right)_{2}$ flakes to $\mathrm{Ba}_{x} \mathrm{Ni}_{3-x}\left(\mathrm{PO}_{4}\right)_{2}$ nanofibers with the addition of $\mathrm{Ni}^{2+}$ ions is observed. The as-prepared nanofiber material shows a diameter less than 10 nanometers and length of several micrometers. The material possesses a BET surface area of $64.8 \mathrm{~m}^{2} \mathrm{~g}^{-1}$. When it is used as a supercapacitor electrode material, specific capacitances as high as $1058 \mathrm{~F} \mathrm{~g}^{-1}$ at $0.5 \mathrm{~A} \mathrm{~g}^{-1}$ and $713 \mathrm{~F} \mathrm{~g}^{-1}$ at $5 \mathrm{~A} \mathrm{~g}^{-1}$ are achieved, indicating the promising energy storage property of this material.

Received 30th March 2016

Accepted 2nd May 2016

DOI: $10.1039 / c 6 r a 08149 e$

www.rsc.org/advances

practice. ${ }^{21}$ One of the methods to improve the energy density of

\section{Introduction}

Materials based on metal phosphates have attracted attention in the scientific community due to their promising performance when used in varying applications including sensors, gas adsorption/desorption, supercapacitors, optoelectronics, lithium-ion batteries etc. ${ }^{1-8}$ Attfield et al. firstly synthesized a series of metal phosphates with a molecular formula of $\mathrm{M}_{11}\left(\mathrm{HPO}_{3}\right)_{8}(\mathrm{OH})_{6}(\mathrm{M}=\mathrm{Zn}$, Co, or Ni) through soft hydrothermal treatments. ${ }^{9}$ Inspired by this work, various phosphates containing different cations or cation combinations like nickel, cobalt, ammonium and sodium, have been synthesized by hydrothermal method. ${ }^{10-15}$ Most metal phosphates have a layered structure. This unique structure characteristic is desired for applications such as energy storage devices which require fast transport of ions.

Supercapacitors, also called electrochemical capacitors, are one of the most efficient energy storage devices that have been used in practice due to their advantages of high power density and ultra-long cycle life. ${ }^{16-20}$ However, current commercial supercapacitors suffer from a limited energy density (less than $10 \mathrm{~W} \mathrm{~h} \mathrm{~kg}^{-1}$ ), which prevents their broader application in

${ }^{a}$ School of Chemistry, Physics and Mechanical Engineering, Science and Engineering Faculty, Queensland University of Technology, Brisbane, QLD 4001, Australia. E-mail: hx.wang@qut.edu.au

${ }^{b}$ Key Laboratory for Soft Chemistry and Functional Materials, School of Chemical Engineering, Nanjing University of Science and Technology, Nanjing, China ${ }^{c}$ School of Materials Science and Engineering, Beihang University, Beijing, China ${ }^{d}$ College of Chemistry and Chemical Engineering, Shanghai University of Engineering Science, Shanghai, China

$\dagger$ Electronic supplementary information (ESI) available. See DOI: 10.1039/c6ra08149e supercapacitors is by employing nanostructured pseudocapacitive electrode materials which possess larger specific surface areas, more active sites and shorter transport/diffusion path for electrolytic ions and electrons compared to bulk materials. ${ }^{22}$

Besides metal oxides which are widely studied as pseudocapacitive materials, ${ }^{23-27}$ limited research has shown that onedimensional (1D) phosphate materials can also be effective supercapacitive materials. Pang et al. reported the supercapacitive performance of phosphite materials based on $\left(\mathrm{M}_{11}\left(\mathrm{HPO}_{3}\right)_{8}(\mathrm{OH})_{6}\right)(\mathrm{M}=\mathrm{Co}, \mathrm{Ni})^{28,29}$ and $\left(\mathrm{Ni}_{20}\left[(\mathrm{OH})_{12}\left(\mathrm{H}_{2} \mathrm{O}\right)_{6}\right]\right.$. $\left.\left[\left(\mathrm{HPO}_{4}\right)_{8}\left(\mathrm{PO}_{4}\right)_{4}\right] \cdot 12 \mathrm{H}_{2} \mathrm{O}\right)^{30}$ which were made by hydrothermal method. Benefiting from the high pressure and heating of hydrothermal reaction condition, the material showed good crystallinity and exhibited higher energy density compared to conventional carbon based materials.

However, more recent studies have shown that amorphous state of nanomaterials may be more beneficial in supercapacitor devices compared to their crystallinity counterpart owing to the higher structural disorder, larger density of active site of the former, leading to higher energy density. Yang et al. reported amorphous $\mathrm{Ni}(\mathrm{OH})_{2}$ nanospheres whose capacitive performance was commensurate with the crystalline materials. $^{31}$ Moreover, Cao et al. reported the supercapacitive performance of ultrathin amorphous $\mathrm{Co}_{3}\left(\mathrm{PO}_{4}\right)_{2}$ nanowires which exhibited higher capacitance than the crystalline counterpart material. ${ }^{32}$

Herein, we report the synthesis of a new phosphate material based on amorphous $\mathrm{Ba}_{x} \mathrm{Ni}_{3-x}\left(\mathrm{PO}_{4}\right)_{2}$ nanofibers with diameter less than 10 nanometres through a facile cation exchange reaction method in aqueous solution at room temperature. By monitoring the phase transformation and growth process of 
$\mathrm{Ba}_{x} \mathrm{Ni}_{3-x}\left(\mathrm{PO}_{4}\right)_{2}$ material by SEM and $\mathrm{XRD}$, we have observed a clear morphology evolution from $\mathrm{Ba}_{3}\left(\mathrm{PO}_{4}\right)_{2}$ microplates to microflowers and finally to $\mathrm{Ba}_{x} \mathrm{Ni}_{3-x}\left(\mathrm{PO}_{4}\right)_{2}$ nanofibers with the increased concentration of $\mathrm{Ni}\left(\mathrm{NO}_{3}\right)_{2}$ in the precursor solution. A growth mechanism which involves self-assembly of $\mathrm{Ba}_{3}\left(\mathrm{PO}_{4}\right)_{2}$ microplates that gradually transformed into $\mathrm{Ba}_{x} \mathrm{Ni}_{3-x}\left(\mathrm{PO}_{4}\right)_{2}$ nanofibers is proposed. The study of argon adsorptiondesorption isotherm shows the as-prepared nanofibers has a large BET surface area of $64.8 \mathrm{~m}^{2} \mathrm{~g}^{-1}$, which provides sufficient active sites for the faradaic charge transfer process when used as electrode materials of SCs. The maximum specific capacitance of $1058 \mathrm{~F} \mathrm{~g}^{-1}$ (at $0.5 \mathrm{Ag}^{-1}$ ) and $713 \mathrm{~F} \mathrm{~g}^{-1}$ (at $5 \mathrm{~A} \mathrm{~g}^{-1}$ ) were obtained, which is much higher than the corresponding crystalline material made by annealing the material at $800{ }^{\circ} \mathrm{C}$. The remarkable capacitance and good electrochemical properties of $\mathrm{Ba}_{x} \mathrm{Ni}_{3-x}\left(\mathrm{PO}_{4}\right)_{2}$ material are attributed to the unique amorphous nanostructure and the efficient faradaic charge transfer process involving the reversible redox reaction of nickel cations.

\section{Experimental}

\section{Materials}

All the chemicals of analytical grade were purchased from Alfa Aesar and used as received without any further purification, unless otherwise stated. Deionized water with a resistivity of 18.2 $\mathrm{M} \Omega \mathrm{cm}$ was used in all reactions. Nickel foams were provided by Sigma-Aldrich.

\section{Preparation of $\mathrm{Ba}_{x} \mathrm{Ni}_{3-x}\left(\mathrm{PO}_{4}\right)_{2}$ nanofibers}

$\mathrm{Ba}_{x} \mathrm{Ni}_{3-x}\left(\mathrm{PO}_{4}\right)_{2}$ nanofibers were prepared through a facile solution method based on cation exchange reaction. In a standard synthesis procedure, $20 \mathrm{mM} \mathrm{Na} \mathrm{NO}_{4} \cdot 12 \mathrm{H}_{2} \mathrm{O}$ aqueous solution was dropwise added into $\mathrm{Ba}\left(\mathrm{NO}_{3}\right)_{2}$ aqueous solution (30 $\mathrm{mM})$ under continuous magnetic stirring. A white precipitate was formed gradually during this process. After $2 \mathrm{~min}$ reaction, $30 \mathrm{mM} \mathrm{Ni}\left(\mathrm{NO}_{3}\right)_{2} \cdot 6 \mathrm{H}_{2} \mathrm{O}$ aqueous solution was further dropwise added into above reaction solution. After $48 \mathrm{~h}$ reaction under continuous vigorous stirring, all white precipitates were found to be transformed into light green colour, which was then collected through centrifuge. The material was rinsed at least three times with large amount of deionized water before being dried at $80^{\circ} \mathrm{C}$ in an electrical oven.

\section{Material characterizations}

The morphology and elemental distributions of the products were characterized by field emission scanning electron microscope (FESEM, JSM-7001F, JEOL) employing an accelerating voltage of $5.00 \mathrm{kV}$ with an energy dispersive spectrometer (EDS). Transmission electron microscope was used to measure the crystallinity and morphology of as-prepared materials (TEM, JEOL 2100). X-ray diffraction analysis (XRD, PANaytical MPD Cu Powder XRD) using $\mathrm{Cu} \mathrm{K} \alpha$ radiation at $40 \mathrm{keV}$ and $40 \mathrm{~mA}$ was employed to determine the crystalline structure and composition of the as-prepared products. X-ray photoelectron spectroscopy (XPS) was used to obtain the elemental composition and valence state, which was performed by a photoelectron spectrometer using a non-monochromatic $\mathrm{Mg} \mathrm{K} \alpha(1253.6 \mathrm{eV}) \mathrm{X}$ ray source (DAR 400, Omicron Nanotechnology) with incident angle at $65^{\circ}$ to the sample surface. The signal was collected by a $125 \mathrm{~mm}$ hemispherical electron energy analyser (Sphera II, 7 channels detector, Omicron Nano-technology). Micromeritics Tristar II 3020 Surface Area Analyser was used to test the BET surface area of the sample.

\section{Electrochemical measurements}

The electrochemical properties of $\mathrm{Ba}_{x} \mathrm{Ni}_{3-x}\left(\mathrm{PO}_{4}\right)_{2}$ nanofibers were comprehensively investigated using a three-electrode configuration cell with as-synthesized material as working electrode, Pt wire as counter electrode and calomel electrode as reference in 2.0 $\mathrm{M} \mathrm{KOH}$ aqueous electrolyte. The working electrodes were fabricated by following a similar procedure reported by other groups previously. ${ }^{33}$ Firstly, a mixture of $\mathrm{Ba}_{x} \mathrm{Ni}_{3-x}\left(\mathrm{PO}_{4}\right)_{2}$ nanofibers, carbon black, and poly(vinylidene fluoride) (PVDF) with mass ratio of $80: 10: 10$ was dissolved in $N$-methylpyrrolidinone (NMP) to make a slurry under continuous stirring for $24 \mathrm{~h}$, which was then pasted on a nickel foam $\left(1 \times 1 \mathrm{~cm}^{2}\right)$. After drying in a vacuum oven at $110{ }^{\circ} \mathrm{C}$ for $10 \mathrm{~h}$, the coated nickel foam was pressed into a thin film under $10 \mathrm{MPa}$ pressure. Each working electrode contained 1-2 mg active material. All the electrochemical properties were performed with an electrochemical workstation (SP-150, BioLogic Science Instruments) at room temperature $\left(22^{\circ} \mathrm{C}\right)$. The electrochemical impedance spectral (EIS) measurements were carried out in the frequency range of $100 \mathrm{kHz}$ to $10 \mathrm{mHz}$ with an AC amplitude of $5 \mathrm{mV}$.

The specific capacitance $\left(C_{\mathrm{T}}\right)$ of the electrode is calculated based on the measured galvanostatic charging/discharging (GCD) curves, according to eqn (1): $:^{34-36}$

$$
C_{\mathrm{T}}=\frac{I}{m \mathrm{~d} V / \mathrm{d} t}
$$

where $I$ (in A) is the discharge current, $m$ (in $g$ ) is the total mass of active materials, $t$ (in second) is the discharge time, $V$ (in V) is the potential during the discharge process and $\mathrm{d} V / \mathrm{d} t$ is the slope of the discharge curve.

\section{Results and discussion}

As stated in experimental section, a white precipitate was firstly observed by addition of $\mathrm{Na}_{3} \mathrm{PO}_{4}$ to $\mathrm{Ba}\left(\mathrm{NO}_{3}\right)_{2}$, which then transformed to light green color by further addition of $\mathrm{Ni}\left(\mathrm{NO}_{3}\right)_{2} \cdot 6 \mathrm{H}_{2} \mathrm{O}$. In order to understand this process, the XRD and SEM of both the white precipitate and the final product of light green precipitate were recorded. The results show that the white precipitate is barium phosphate $\left(\mathrm{Ba}_{3}\left(\mathrm{PO}_{4}\right)_{2}\right.$, Fig. $\left.\mathrm{S} 1(\mathrm{a}) \dagger\right)$, which adopts rhombohedral crystal phase (PDF\#80-1615) and shows good crystallinity. SEM image shows the barium phosphate has a regular shape of hexagon plate with size of several micro-meters (Fig. S1(b) $\dagger$ ). The nature of $\mathrm{Ba}_{3}\left(\mathrm{PO}_{4}\right)_{2}$ white precipitate is also confirmed by the selected area electron 

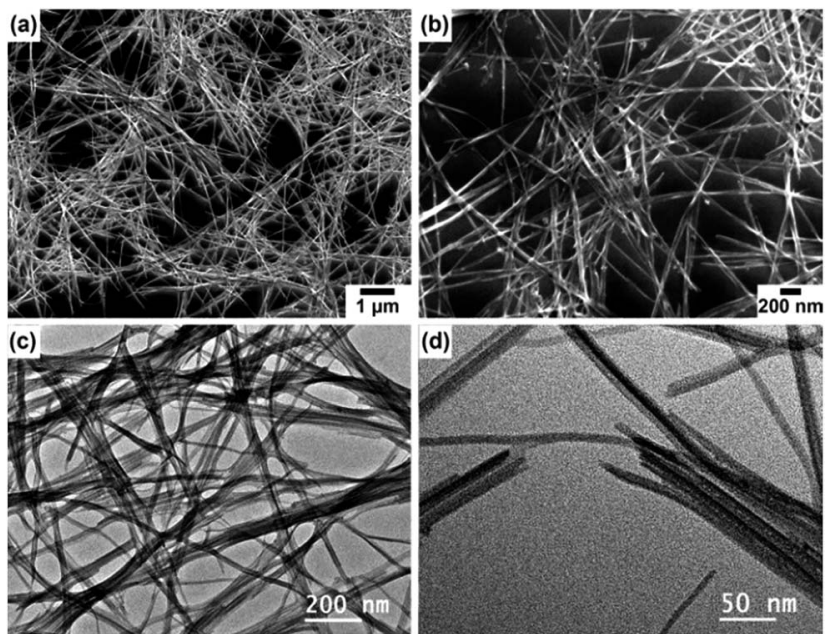

Fig. 1 (a and b) SEM images of $\mathrm{Ba}_{x} \mathrm{Ni}_{3-x}\left(\mathrm{PO}_{4}\right)_{2}$ nanofibers; (c and d) regular and enlarged TEM images of $\mathrm{Ba}_{x} \mathrm{Ni}_{3-x}\left(\mathrm{PO}_{4}\right)_{2}$ nanofibers.

diffraction (SAED) pattern (Fig. S1(c) †) and high resolution transmission electron microscope (HRTEM, Fig. S1(d)†).

The SEM images of the light green precipitate shown in Fig. 1(a and $\mathrm{b})$ confirm that the final products consist of nanofibers which are micrometer in length and nanometer in width. The TEM images (shown in Fig. 1(c and d)) further reveal that the nanofibers are bundled together and each fiber is less than ten nanometers in diameter. The as-prepared nanofibers show an amorphous nature because no lattice fringe could be detected by the HRTEM image as shown in Fig. 2. The corresponding SAED pattern further confirms their amorphous structure (inset in Fig. 2). In order to confirm the elemental composition of as-prepared nanofibers, EDS was carried out and the result is shown in Fig. S2 (ESI $\dagger$ ). Elements including Ba, $\mathrm{Ni}, \mathrm{P}$, and $\mathrm{O}$ are clearly detected in the EDS profile with the ratio of $\mathrm{Ba} / \mathrm{Ni}=4: 7$, confirming the chemical composition of the obtained material. Above result confirms the partial replacement of $\mathrm{Ba}^{2+}$ in $\mathrm{Ba}_{3}\left(\mathrm{PO}_{4}\right)_{2}$ by $\mathrm{Ni}^{2+}$ during the transformation from white precipitate to light green product.

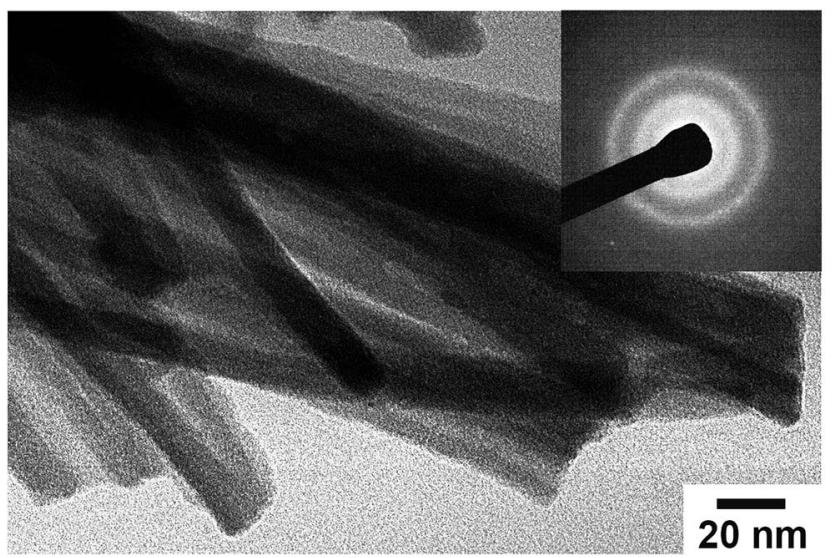

Fig. 2 HRTEM image and corresponded SAED pattern of $\mathrm{Ba}_{x} \mathrm{Ni}_{3-x}(-$ $\left.\mathrm{PO}_{4}\right)_{2}$ nanofibers.

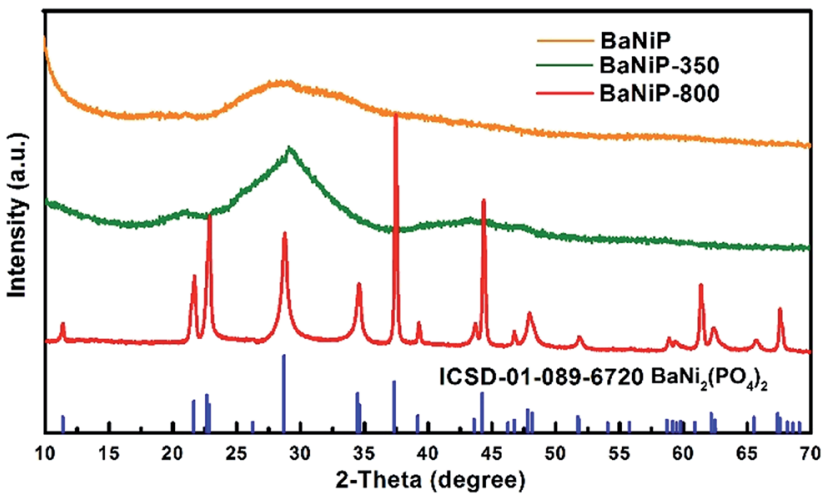

Fig. 3 XRD patterns of fresh $\mathrm{Ba}_{x} \mathrm{Ni}_{3-x}\left(\mathrm{PO}_{4}\right)_{2}$ nanofibers and annealed products at different temperature $\left(350{ }^{\circ} \mathrm{C}\right.$ and $\left.800{ }^{\circ} \mathrm{C}\right)$.

The XRD patterns of as-prepared $\mathrm{Ba}_{x} \mathrm{Ni}_{3-x}\left(\mathrm{PO}_{4}\right)_{2}$ are shown in Fig. 3. Apparently, only a broad and weak diffraction pattern is observed with the fresh product (named as BaNiP), which is in agreement with the HRTEM result shown in Fig. 2, confirming the amorphous nature of the as-synthesized material. This is probably related with the low synthesis temperature process used. To confirm this, a high temperature calcination was employed to investigate the crystallization process of assynthesized materials. The XRD of the material annealed at $350{ }^{\circ} \mathrm{C}$ for $2 \mathrm{~h}$ in air (referred as BaNiP-350, green line) shows that the broad diffraction peak in BaNiP becomes narrower. Meanwhile, several additional broad peaks are observed in the XRD pattern of BaNiP-350, which suggests the crystallinity of the material is improved with the annealing at $350{ }^{\circ} \mathrm{C}$ but it is still poor. By further increasing the annealing temperature to $800{ }^{\circ} \mathrm{C}$, the XRD peaks of the obtained product (named as BaNiP-800) are strong and sharp. All the peaks of the XRD pattern can be well indexed to the crystal structure of rhombohedral $\mathrm{BaNi}_{2}\left(\mathrm{PO}_{4}\right)_{2}$ (ICSD-01-089-6720). The absence of other peaks detected in the XRD pattern of BaNi-800 demonstrates the high purity of the material.

Furthermore, XPS was employed to analyse the surface composition and oxidation state of $\mathrm{Ba}_{x} \mathrm{Ni}_{3-x}\left(\mathrm{PO}_{4}\right)_{2}$ nanofibres, in which $\mathrm{C} 1 \mathrm{~s}(284.8 \mathrm{eV})$ was used to calibrate the binding energies. As shown in Fig. 4(a), the full range XPS spectrum clearly shows the characteristic peaks of $\mathrm{Ni}, \mathrm{Ba}, \mathrm{P}, \mathrm{O}$ and $\mathrm{C}$ elements. It is worth noting that the $\mathrm{C}$ element comes from the residual carbon-based contaminants instead of the as-prepared $\mathrm{Ba}_{x} \mathrm{Ni}_{3-x}\left(\mathrm{PO}_{4}\right)_{2}$ nanofibres. The high resolution XPS (HRXPS) spectrum of Ni 2p (Fig. 4(b)) shows the binding energy peaks at $872.7 \mathrm{eV}$ and $855.0 \mathrm{eV}$, which are corresponding to $\mathrm{Ni} 2 \mathrm{p}_{1 / 2}$ and $\mathrm{Ni} 2 \mathrm{p}_{3 / 2}$, respectively, indicating that nickel cations are $\mathrm{Ni}^{2+}$ binding state. ${ }^{37}$ It is worth to note that the intensive shoulder peaks ( 860.1 and $879.1 \mathrm{eV}$, marked as Sat 1 and Sat 2) along with the main peaks of $\mathrm{Ni} 2 \mathrm{p}_{3 / 2}$ and $\mathrm{Ni} 2 \mathrm{p}_{1 / 2}$ are due to two shakeuptype peaks of nickel. ${ }^{38}$ Fig. 4 (c) presents the HRXPS spectrum of Ba $3 \mathrm{~d}_{1 / 2}$ and $\mathrm{Ba} 3 \mathrm{~d}_{5 / 2}$ with the characteristic peaks detected at $795.0 \mathrm{eV}$ and $779.6 \mathrm{eV}$, respectively. The peak positions and binding energy gap between the two signals clearly demonstrate the existence of $\mathrm{Ba}^{2+} \cdot{ }^{39-41}$ Moreover, the HRXPS spectra in 

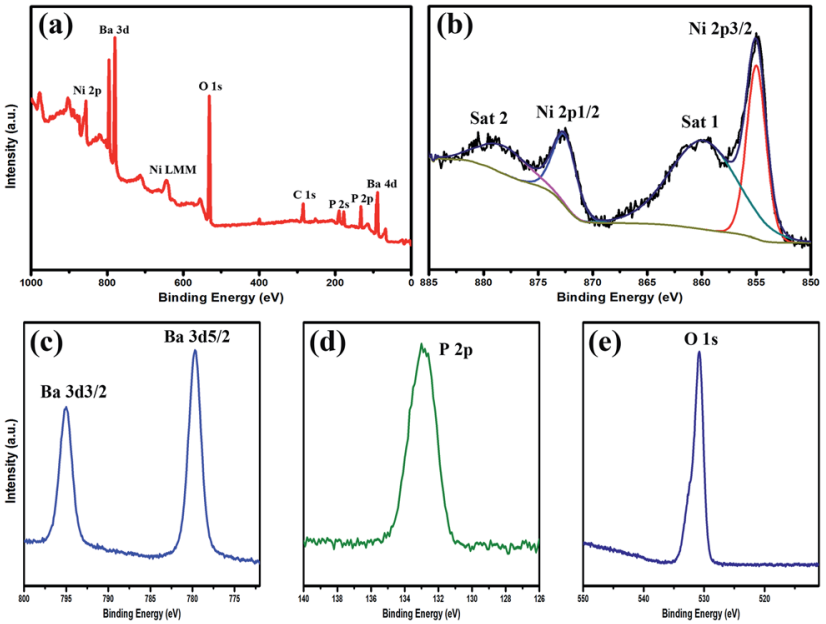

Fig. 4 (a) Full range XPS spectrum of $\mathrm{Ba}_{x} \mathrm{Ni}_{3-x}\left(\mathrm{PO}_{4}\right)_{2}$ nanofibers; (b-e) HRXPS spectra of $\mathrm{Ba}, \mathrm{Ni}, \mathrm{P}$, and $\mathrm{O}$ elements.

Fig. 4(d) and (e) show the state $\mathrm{P} 2 \mathrm{p}$ and $\mathrm{O} 1 \mathrm{~s}$ with the binding energy at 132.8 and $530.7 \mathrm{eV}$, respectively, further confirming the formation of $\mathrm{Ba}_{x} \mathrm{Ni}_{3-x}\left(\mathrm{PO}_{4}\right)_{2}$ nanomaterials. ${ }^{42}$

During the process of fabrication of $\mathrm{Ba}_{x} \mathrm{Ni}_{3-x}\left(\mathrm{PO}_{4}\right)_{2}$ nanofiber, we noticed that the content of precursor $\mathrm{Ni}\left(\mathrm{NO}_{3}\right)_{2}$ plays a key role in the formation of nanofibers. Fig. 5 and $\mathrm{S} 3 \uparrow$ show the SEM images and XRD patterns of $\mathrm{Ba}_{x} \mathrm{Ni}_{3-x}\left(\mathrm{PO}_{4}\right)_{2}$ material synthesized with different concentration of $\mathrm{Ni}\left(\mathrm{NO}_{3}\right)_{2}$. When the content of $\mathrm{Ni}\left(\mathrm{NO}_{3}\right)_{2}$ is only $5 \mathrm{mM}$, the product consists of material with microflower structure (Fig. 5(a)), which is believed due to the self-assembly of partially reacted $\mathrm{Ba}_{3}\left(\mathrm{PO}_{4}\right)_{2}$ flakes. By increasing the concentration of $\mathrm{Ni}\left(\mathrm{NO}_{3}\right)_{2}$ solution to $10 \mathrm{mM}$, the mircroflowers are disassembled and lots of flakes are found in the material (Fig. 5(b)). Further increase the concentration of $\mathrm{Ni}\left(\mathrm{NO}_{3}\right)_{2}$ to $20 \mathrm{mM}$ in the precursor solution, nanofibers start to form among the main morphology of flakes which are interweaved together as indicated in Fig. 5(c). The flakes are completely transformed into nanofibers when $30 \mathrm{mM} \mathrm{Ni}\left(\mathrm{NO}_{3}\right)_{2}$
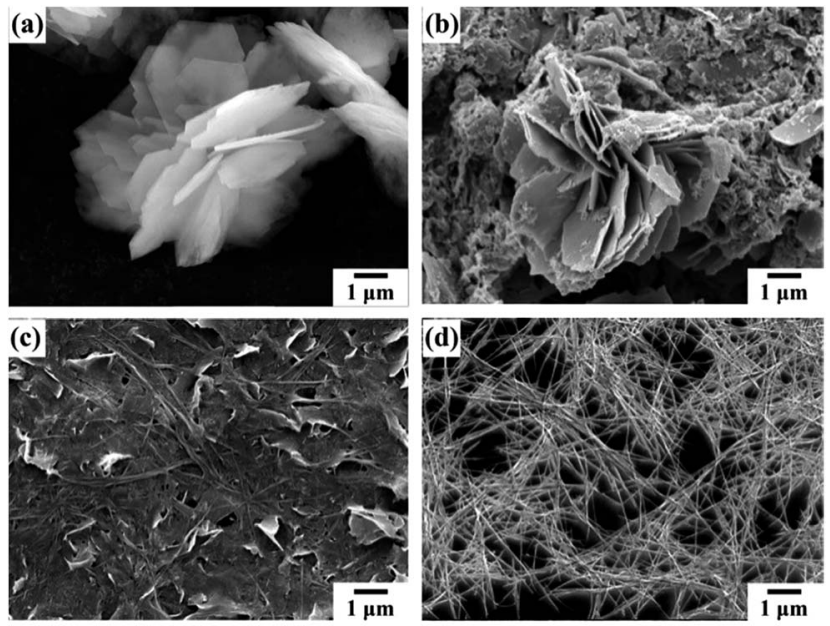

Fig. 5 SEM images of $\mathrm{Ba}_{x} \mathrm{Ni}_{3-x}\left(\mathrm{PO}_{4}\right)_{2}$ material synthesized from different concentration of $\mathrm{Ni}\left(\mathrm{NO}_{3}\right)_{2}$ of $5 \mathrm{mM}$ (a), $10 \mathrm{mM}$ (b), $20 \mathrm{mM}$ (c), $30 \mathrm{mM}(\mathrm{d})$ is used in the reaction solution (Fig. 5(d)). Beyond this, the morphology of the material does not change. XRD results (Fig. S3†) confirm strong diffraction peaks of $\mathrm{Ba}_{3}\left(\mathrm{PO}_{4}\right)_{2}$ flakes when $10 \mathrm{mM} \mathrm{Ni}\left(\mathrm{NO}_{3}\right)_{2}$ is used in the reaction. A complete transformation from $\mathrm{Ba}_{3}\left(\mathrm{PO}_{4}\right)_{2}$ into $\mathrm{Ba}_{x} \mathrm{Ni}_{3-x}\left(\mathrm{PO}_{4}\right)_{2}$ nanofibers occurs when the concentration of $\mathrm{Ni}\left(\mathrm{NO}_{3}\right)_{2}$ solution is over 30 $\mathrm{mM}$ along with the disappearance of the characteristic XRD peaks of $\mathrm{Ba}_{3}\left(\mathrm{PO}_{4}\right)_{2}$.

In order to further understand the formation mechanism of the nanofibers, the SEM images of $\mathrm{Ba}_{x} \mathrm{Ni}_{3-x}\left(\mathrm{PO}_{4}\right)_{2}$ with different reaction time were recorded and are shown in Fig. 6 . It can be seen that the smooth surface of pristine $\mathrm{Ba}\left(\mathrm{PO}_{4}\right)_{2}$ material becomes rough within only 5 min reaction (Fig. 6(a)). Further elongation of the reaction duration, $\mathrm{Ba}_{3}\left(\mathrm{PO}_{4}\right)_{2}$ microplates turn into fluffy and some of them merge together to form thin films gradually (Fig. 6(b)). Nanofibers start to form on the amorphous films after $2 \mathrm{~h}$ reaction (Fig. 6(c) and inset). Further extending the reaction to $48 \mathrm{~h}$ leads to the full transformation of all the material into nanofibers (Fig. 6(d)).

Based on the above results, the formation mechanism of the nanofibers is proposed as shown in Scheme 1. It is known that $\mathrm{Ba}_{3}\left(\mathrm{PO}_{4}\right)_{2}$ adopts a layer-structure with a characteristic of rod sequence of polyhedral in the form of $\mathrm{PO}_{4}-\mathrm{Ba}(2) \mathrm{O}_{10}-\mathrm{Ba}(1) \mathrm{O}_{12^{-}}$ $\mathrm{Ba}(2) \mathrm{O}_{10}-\mathrm{PO}_{4}$ along the $c$ axis. ${ }^{43-45}$ The weak bonding strength between $\mathrm{Ba}^{2+}$ and oxygen makes $\mathrm{Ba}^{2+}$ easy to be substituted by other divalent cations. This explains the partial substitution of $\mathrm{Ba}^{2+}$ by $\mathrm{Ni}^{2+}$ in the cations exchange process. In this process, the added $\mathrm{Ni}^{2+}$ firstly intercalates into the interlayer of the microplated structure of $\mathrm{Ba}_{3}\left(\mathrm{PO}_{4}\right)_{2}$. The subsequent cation exchange reaction results in the formation of a rough surface of the original $\mathrm{Ba}_{3}\left(\mathrm{PO}_{4}\right)_{2}$ flakes in the first few minutes of reaction. As more $\mathrm{Ni}^{2+}$ ions intercalate into the host, the layered structure is expanded and finally set apart into thin layered films (Fig. 6(b)). Sufficient $\mathrm{Ni}^{2+}$ ions are critical in this process to ensure fully penetration and separation of all the pristine $\mathrm{Ba}_{3}\left(\mathrm{PO}_{4}\right)_{2}$ layers. It is expected that the replacement of $\mathrm{Ba}^{2+}$ should occur along the $c$ axis direction by considering the molecule structure of $\mathrm{Ba}_{3}\left(\mathrm{PO}_{4}\right)_{2}$, which is responsible for the formation of nanofiber
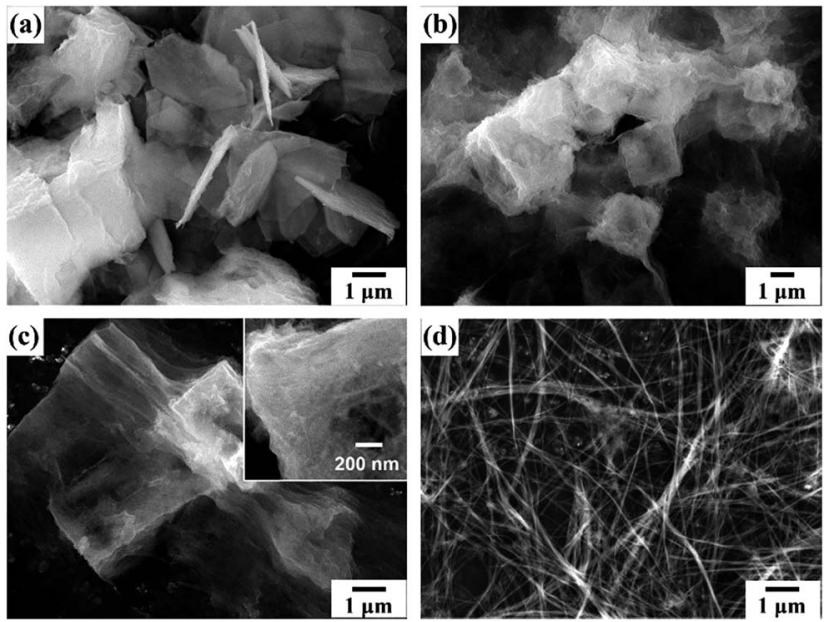

Fig. 6 SEM images of $\mathrm{Ba}_{x} \mathrm{Ni}_{3-x}\left(\mathrm{PO}_{4}\right)_{2}$ materials with different reaction time of $5 \mathrm{~min}(\mathrm{a}), 30 \mathrm{~min}(\mathrm{~b}), 2 \mathrm{~h}$ (c) and $48 \mathrm{~h}$ (d). 


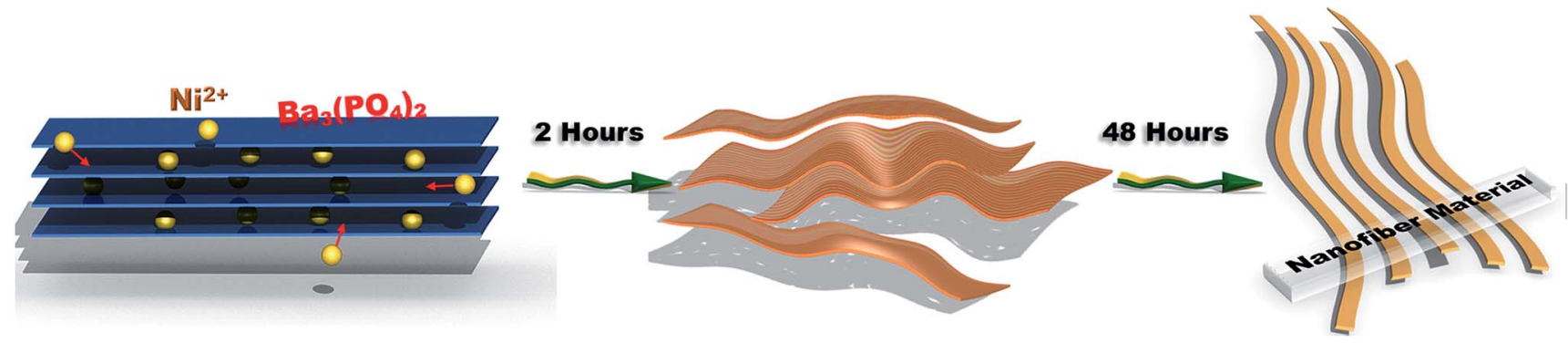

Scheme 1 Schematic illustration of the formation of $\mathrm{Ba}_{x} \mathrm{Ni}_{3-x}\left(\mathrm{PO}_{4}\right)_{2}$ nanofiber.

structure (Fig. 6(c)). The long intensively magnetic stirring further facilitates split of the weakly bonded films into nanofibers.

The energy storage properties of as-synthesized $\mathrm{Ba}_{x} \mathrm{Ni}_{3-x}$ $\left(\mathrm{PO}_{4}\right)_{2}$ nanofibers were investigated in a typical three-electrode electrochemical system. The cyclic voltammetry (CV) and GCD plots of $\mathrm{Ba}_{x} \mathrm{Ni}_{3-x}\left(\mathrm{PO}_{4}\right)_{2}$ nanofiber electrode are shown in Fig. 7(a and b), respectively. It can be seen from Fig. 7(a) that a distinct pair of oxidation and reduction peaks can be clearly observed in the CV plots with different scan rates, demonstrating a strong pseudocapacitive behaviour. ${ }^{46}$ The pseudocapacitance should be originated from the redox reaction of $\mathrm{Ni}^{2+}$ / $\mathrm{Ni}^{3+}$ during the faradaic charge transfer process other than $\mathrm{Ba}^{2+}$ considering the sole valence state of the cations of barium. ${ }^{47,48}$ Moreover, the high current response in the $\mathrm{CV}$ curves indicates that $\mathrm{Ba}_{x} \mathrm{Ni}_{3-x}\left(\mathrm{PO}_{4}\right)_{2}$ nanofibers possess considerable charge storage capability.

The GCD plots under different charging current densities (Fig. 7(b)) further confirm the pseudo-capacitive behaviours of the electrode material with two distinct plateaus during the charging/discharging process. The specific capacitance of $\mathrm{Ba}_{x^{-}}$ $\mathrm{Ni}_{3-x}\left(\mathrm{PO}_{4}\right)_{2}$ nanofiber electrode under various discharging
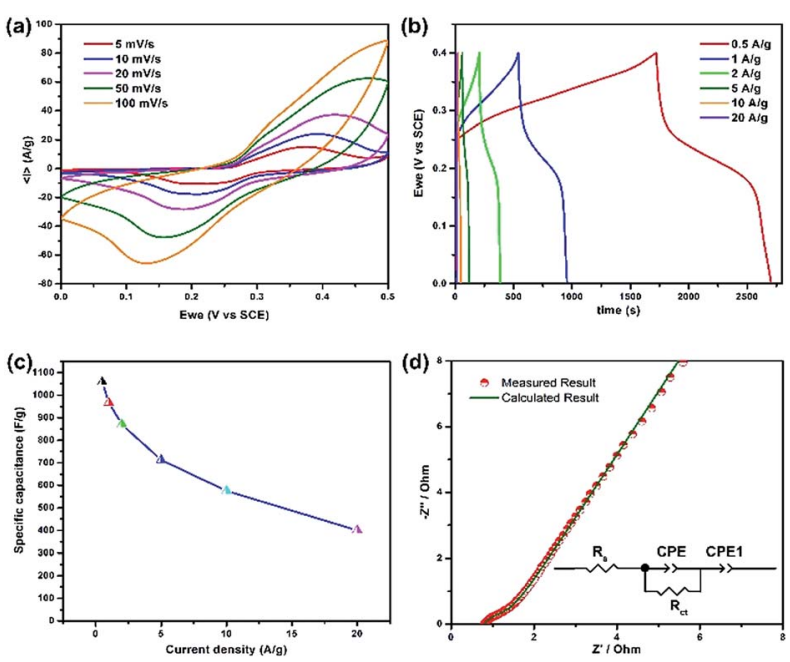

Fig. 7 ( $\mathrm{a}$ and b) The cyclic voltammetry and galvanostatic charging/ discharging curves of $\mathrm{Ba}_{x} \mathrm{Ni}_{3-x}\left(\mathrm{PO}_{4}\right)_{2}$ nanofiber electrode in $2 \mathrm{M} \mathrm{KOH}$ electrolyte, respectively; (c) calculated specific capacitance of $\mathrm{Ba}_{x}$ $\mathrm{Ni}_{3-x}\left(\mathrm{PO}_{4}\right)_{2} ;$ (d) Nyquist plot of the impedance of $\mathrm{Ba}_{x} \mathrm{Ni}_{3-x}\left(\mathrm{PO}_{4}\right)_{2}$ electrode from $0.01 \mathrm{~Hz}$ to $100 \mathrm{kHz}$. current densities was calculated according to the GCD curves. As shown in Fig. 7(c), the specific capacitance of the electrode is $1058,968,870,713,575$ and $400 \mathrm{~F} \mathrm{~g}^{-1}$ at the discharging current density of $0.5,1,2,5,10$ and $20 \mathrm{~A} \mathrm{~g}^{-1}$, respectively. Clearly, the electrode retains over $50 \%$ of the initial capacitance even when the discharging current density is increased by 20 times from $0.5 \mathrm{~A} \mathrm{~g}^{-1}$ to $10 \mathrm{~A} \mathrm{~g}^{-1}$, indicating a good rate capability. This is ascribed to the high conductivity of the material as confirmed by electrochemical impedance spectrum (EIS) of the electrode in Fig. 7(d). The EIS data was fitted using an equivalent circuit by Zview software. As shown in the inset of Fig. 7(d), the equivalent circuit consists of a series resistance $R_{\mathrm{S}}$, a chargetransfer resistance $R_{\mathrm{ct}}$, and constant phase elements CPE and CPE1 corresponding to a pseudocapacitance of the electrode and double-layer capacitance at the electrode material/ electrolyte interface, respectively. ${ }^{49}$ The EIS fitting results show that the synthesized $\mathrm{Ba}_{x} \mathrm{Ni}_{3-x}\left(\mathrm{PO}_{4}\right)_{2}$ nanofiber electrode has a low series resistance $\left(R_{\mathrm{s}}=0.80 \Omega\right)$ and charge transfer resistance $\left(R_{\mathrm{ct}}=0.56 \Omega\right)$, which is believed to be one of the reasons for the excellent supercapacitive performance of the material.

The cycling performance of the as-prepared electrode is also studied. As shown in Fig. 8, around $80 \%$ of the initial capacitance of the electrode is retained after 500 cycles at a discharging current of $3 \mathrm{~A} \mathrm{~g}^{-1}$, indicating a relatively good cycling stability. However compared to other reported crystalline

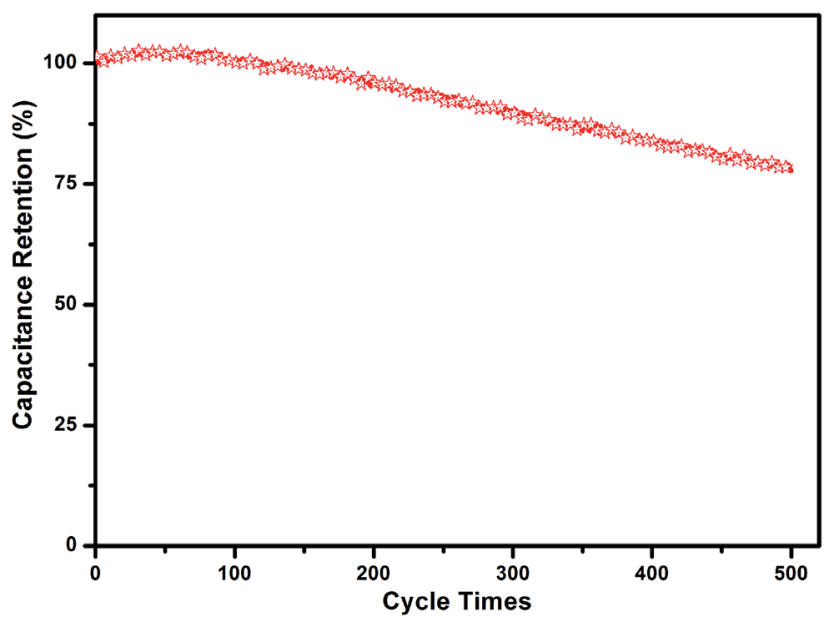

Fig. 8 Cycling stability test of $\mathrm{Ba}_{x} \mathrm{Ni}_{3-x}\left(\mathrm{PO}_{4}\right)_{2}$ material synthesized from $30 \mathrm{mM} \mathrm{Ni}\left(\mathrm{NO}_{3}\right)_{2}$. 
phosphates materials, ${ }^{27-29}$ further improvement of the cycling stability of the material is needed. In order to understand the reason for the unsatisfactory stability of the material, the SEM image of the working material after 500 cycles was recorded (Fig. $\mathrm{S} 4 \dagger$ ). It is found that the nanofiber structure of the synthesized $\mathrm{Ba}_{x} \mathrm{Ni}_{3-x}\left(\mathrm{PO}_{4}\right)_{2}$ is destroyed after the stability test. This suggests a large volume change occurring within the material during the charging/discharging process, which results in the broken of nanofiber structure into pieces. Previous work by other researchers have shown that incorporation of more conductive and stable materials such as carbon materials or metal oxides can normally improve the stability and electrochemical performance of non-carbon materials. ${ }^{50,51}$ This will be the subject of our future research.

The remarkable supercapacitive performance of the synthesized $\mathrm{Ba}_{x} \mathrm{Ni}_{3-x}\left(\mathrm{PO}_{4}\right)_{2}$ nanofibers is attributed to the unique amorphous nanostructure and large surface area. The argon adsorption-desorption isotherm plot reveals that $\mathrm{Ba}_{x} \mathrm{Ni}_{3-x}(-$ $\left.\mathrm{PO}_{4}\right)_{2}$ nanofibers have a high BET surface area of $64.8 \mathrm{~m}^{2} \mathrm{~g}^{-1}$ (Fig. 9). As shown in Fig. S5, $\uparrow$ the amorphous sample owns a 3 times higher current peak than the crystalline material $\left(800{ }^{\circ} \mathrm{C}\right.$ annealed sample) in the cyclic voltammetry measurement, confirming the superior energy storage property of the amorphous structure. Similar phenomenon has been reported by $\mathrm{Li}$ et al. who found superior supercapacitive performance with a series of amorphous $\mathrm{Ni}-\mathrm{Co}-\mathrm{Fe}$ hydroxides. ${ }^{52}$ It is ascribed to the unique nature of amorphous materials which is disorder in long-range but is structurally order in short-range. Moreover amorphous material possesses much more unsaturated ligand atoms and efficient electrochemically active sites compared to crystalline counterpart. ${ }^{52}$ These features favour the charge transport process in the material. This is confirmed by the low interface charge transfer resistance and good rate ability of the $\mathrm{Ba}_{x} \mathrm{Ni}_{3-x}\left(\mathrm{PO}_{4}\right)_{2}$ material shown above. Moreover, the relatively large surface area provides sufficient pathway for the transport of charged ions, which further boosts the supercapacitive performance of the material.

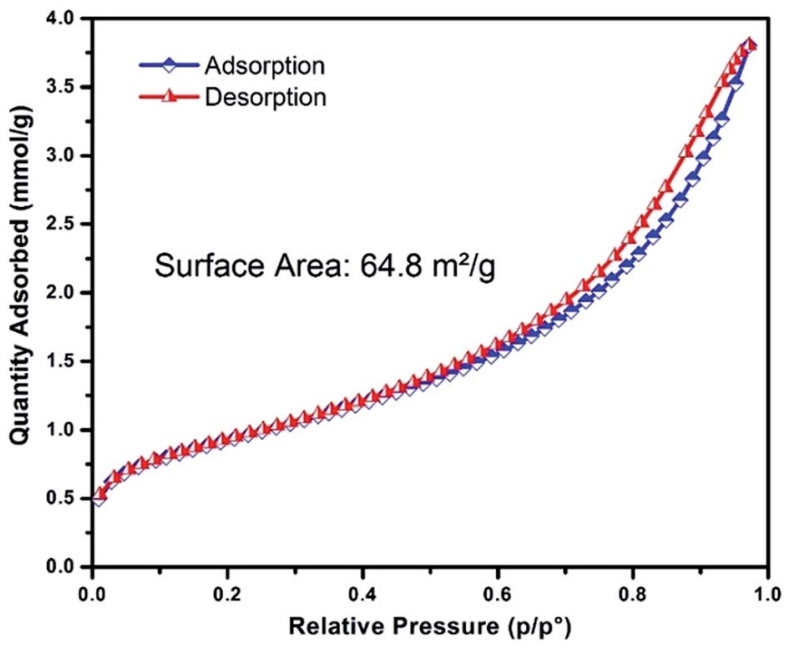

Fig. 9 Argon adsorption-desorption isotherm linear plot of $\mathrm{Ba}_{x}-$ $\mathrm{Ni}_{3-x}\left(\mathrm{PO}_{4}\right)_{2}$ material.

\section{Conclusions}

In summary, nanofiber-structured amorphous $\mathrm{Ba}_{x} \mathrm{Ni}_{3-x}\left(\mathrm{PO}_{4}\right)_{2}$ material has been synthesized for the first time through a facile cation-exchange reaction method at room temperature. The asprepared materials exhibited typical pseudocapacitive behaviour with high electrical storage capacity. The specific capacitance of $1058 \mathrm{~F} \mathrm{~g}^{-1}$ at a discharging current density of $0.5 \mathrm{~A} \mathrm{~g}^{-1}$ was achieved. The good electrochemical properties of $\mathrm{Ba}_{x}$ $\mathrm{Ni}_{3-x}\left(\mathrm{PO}_{4}\right)_{2}$ materials are attributed to the ultrafine amorphous nanofiber structure and high surface area of $64.8 \mathrm{~m}^{2} \mathrm{~g}^{-1}$. Just as other pseudocapacitive materials, the cycling stability of individual $\mathrm{Ba}_{x} \mathrm{Ni}_{3-x}\left(\mathrm{PO}_{4}\right)_{2}$ material also needs to be improved for further application in supercapacitors. The investigation of the formation mechanism shows that the concentration of precursor $\mathrm{Ni}\left(\mathrm{NO}_{3}\right)_{2}$ solution plays a critical role in the formation of the nanofiber structure. The method of synthesizing nanostructured phosphate materials using cation exchange reaction paves a facile way for synthesis of materials with controlled morphology and good electrochemical properties to meet the high-energy density requirement of practical applications in energy storage systems, such as high-performance supercapacitors.

\section{Acknowledgements}

H. W. acknowledges financial support from the Australian Research Council (ARC) Future Fellowship (FT120100674) for this work. T. W. thanks Queensland University of Technology (QUT) for Postgraduate Research Award scholarships.

\section{Notes and references}

1 C. Wu, X. Lu, L. Peng, K. Xu, X. Peng, J. Huang, G. Yu and Y. Xie, Nat. Commun., 2013, 4, 2431.

2 J.-H. Yang, J. Tan and D. Ma, J. Power Sources, 2014, 260, 169173.

3 C. Sun, S. Rajasekhara, J. B. Goodenough and F. Zhou, J. Am. Chem. Soc., 2011, 133, 2132-2135.

4 C. Chen, W. Chen, J. Lu, D. Chu, Z. Huo, Q. Peng and Y. Li, Angew. Chem., Int. Ed. Engl., 2009, 48, 4816-4819.

5 I.-S. Cho, D. W. Kim, S. Lee, C. H. Kwak, S.-T. Bae, J. H. Noh, S. H. Yoon, H. S. Jung, D.-W. Kim and K. S. Hong, Adv. Funct. Mater., 2008, 18, 2154-2162.

6 F. Zhang, Z. Zhao, R. Tan, Y. Guo, L. Cao, L. Chen, J. Li, W. Xu, Y. Yang and W. Song, J. Colloid Interface Sci., 2012, 386, 277-284.

7 S. Tamura, N. Imanaka, M. Kamikawa and G. Adachi, Adv. Mater., 2000, 12, 898-901.

8 K. Ding, H. Gu, C. Zheng, L. Liu, L. Liu, X. Yan and Z. Guo, Electrochim. Acta, 2014, 146, 585-590.

9 M. D. Marcos, P. Amoros, A. Beltran-Porter, R. MartinezManez and J. P. Attfield, Chem. Mater., 1993, 5, 121-128.

10 X. Liu, Y. Xing, X. Wang, H. Xu, X. Liu, K. Shao and Z. Su, Chem. Commun., 2010, 46, 2614-2616.

11 Z. Gu, T. Zhai, B. Gao, G. Zhang, D. Ke, Y. Ma and J. Yao, Cryst. Growth Des., 2007, 7, 825-830. 
12 Y. Ni, K. Liao, J. Hong and X. Wei, CrystEngComm, 2009, 11, 570-575.

13 H. Pang, S. Wang, W. Shao, S. Zhao, B. Yan, X. Li, S. Li, J. Chen and W. Du, Nanoscale, 2013, 5, 5752-5757.

14 J. Zhao, H. Pang, J. Deng, Y. Ma, B. Yan, X. Li, S. Li, J. Chen and W. Wang, CrystEngComm, 2013, 15, 5950-5955.

15 X. Sun, Y. Xing, X. Liu, B. Liu and S. Hou, Dalton Trans., 2010, 39, 1985-1988.

16 J. Chmiola, G. Yushin, Y. Gogotsi, C. Portet, P. Simon and P. L. Taberna, Science, 2006, 313, 1760-1763.

17 G. Wang, L. Zhang and J. Zhang, Chem. Soc. Rev., 2012, 41, 797-828.

18 I. E. Rauda, V. Augustyn, B. Dunn and S. H. Tolbert, Acc. Chem. Res., 2013, 46, 1113-1124.

19 L. L. Zhang and X. S. Zhao, Chem. Soc. Rev., 2009, 38, 25202531.

20 X. Lu, M. Yu, G. Wang, Y. Tong and Y. Li, Energy Environ. Sci., 2014, 7, 2160-2181.

21 P. Simon and Y. Gogotsi, Nat. Mater., 2008, 7, 845-854.

22 Y. Shi, L. Peng, Y. Ding, Y. Zhao and G. Yu, Chem. Soc. Rev., 2015, 44, 6684-6696.

23 L. Li, S. Peng, H. B. Wu, L. Yu, S. Madhavi and X. W. D. Lou, Adv. Energy Mater., 2015, 5, 1500753.

24 Z. Fan, J. Yan, T. Wei, L. Zhi, G. Ning, T. Li and F. Wei, Adv. Funct. Mater., 2011, 21, 2366-2375.

25 S. Peng, L. Li, H. B. Wu, S. Madhavi and X. W. Lou, Adv. Energy Mater., 2014, 1401172.

26 H. Xu, X. Hu, H. Yang, Y. Sun, C. Hu and Y. Huang, Adv. Energy Mater., 2014, 1401882.

27 X. Lu, T. Zhai, X. Zhang, Y. Shen, L. Yuan, B. Hu, L. Gong, J. Chen, Y. Gao, J. Zhou, Y. Tong and Z. L. Wang, Adv. Mater., 2012, 24, 938-944.

28 H. Pang, Y. Liu, J. Li, Y. Ma, G. Li, Y. Ai, J. Chen, J. Zhang and H. Zheng, Nanoscale, 2013, 5, 503-507.

29 H. Pang, C. Wei, Y. Ma, S. Zhao, G. Li, J. Zhang, J. Chen and S. Li, ChemPlusChem, 2013, 78, 546-553.

30 J. Zhao, S. Wang, Z. Run, G. Zhang, W. Du and H. Pang, Part. Part. Syst. Charact., 2015, 32, 880-885.

31 H. B. Li, M. H. Yu, F. X. Wang, P. Liu, Y. Liang, J. Xiao, C. X. Wang, Y. X. Tong and G. W. Yang, Nat. Commun., 2013, 4, 1894.
32 Y. Xi, B. Dong, Y. Dong, N. Mao, L. Ding, L. Shi, R. Gao, W. Liu, G. Su and L. Cao, Chem. Mater., 2016, 28, 1355-1362.

33 C. Hao, F. Wen, J. Xiang, L. Wang, H. Hou, Z. Su, W. Hu and Z. Liu, Adv. Funct. Mater., 2014, 24, 6700-6707.

34 X. Cao, B. Zheng, W. Shi, J. Yang, Z. Fan, Z. Luo, X. Rui, B. Chen, Q. Yan and H. Zhang, Adv. Mater., 2015, 27, 46954701.

35 X. Xia, J. Tu, Y. Zhang, X. Wang, C. Gu, X. B. Zhao and H. J. Fan, ACS Nano, 2012, 6, 5531-5538.

36 J. Zhang and X. S. Zhao, ChemSusChem, 2012, 5, 818-841.

37 S. Baskar, Z. Khan, S. Park, K. Kim, H. Ko and Y. Kim, J. Mater. Chem. A, 2015, 3, 21553-21561.

38 X.-F. Lu, D.-J. Wu, R.-Z. Li, Q. Li, S.-H. Ye, Y.-X. Tong and G.-R. Li, J. Mater. Chem. A, 2014, 2, 4706-4713.

39 R. Li, X. Tao and X. Li, J. Mater. Chem., 2009, 19, 983-987.

40 S. Nayak, B. Sahoo, T. K. Chaki and D. Khastgir, RSC Adv., 2014, 4, 1212-1224.

41 M. Prabu and K. Ramalingam, RSC Adv., 2015, 5, 1855418564.

42 C. Wei, C. Cheng, S. Wang, Y. Xu, J. Wang and H. Pang, Chem.-Asian J., 2015, 10, 1731-1737.

43 A. M. Lazarin and C. Airoldi, Anal. Chim. Acta, 2004, 523, 8995.

44 K. Sugiyama and M. Tokonami, Mineral. J., 1990, 15, 141146.

45 S. Zhai, C.-C. Lin and W. Xue, Vib. Spectrosc., 2014, 70, 6-11. 46 G. Gao, H. B. Wu, S. Ding, L. M. Liu and X. W. Lou, Small, 2015, 11, 804-808.

47 K.-W. Nam and K.-B. Kim, J. Electrochem. Soc., 2002, 149, A346-A354.

48 B. Wang, J. S. Chen, Z. Wang, S. Madhavi and X. W. D. Lou, Adv. Energy Mater., 2012, 2, 1188-1192.

49 S. D. Perera, X. Ding, A. Bhargava, R. Hovden, A. Nelson, L. F. Kourkoutis and R. D. Robinson, Chem. Mater., 2015, 27, 7861-7873.

50 S. Guo, J. Liu, S. Qiu, W. Liu, Y. Wang, N. Wu, J. Guo and Z. Guo, J. Mater. Chem. A, 2015, 3, 23895-23904.

51 Y. Wang, H. Wei, J. Wang, J. Liu, J. Guo, X. Zhang, B. L. Weeks, T. D. Shen, S. Wei and Z. Guo, J. Mater. Chem. A, 2015, 3, 20778-20790.

52 H. Li, Y. Gao, C. Wang and G. Yang, Adv. Energy Mater., 2015, 5, 1401767. 